\title{
Evaluating the Effectiveness of Switching to Insulin Degludec from Other Basal Insulins in a Real-World Canadian Population with Type 1 or Type 2 Diabetes: The CAN-TREAT Study
}

\author{
Stewart B. Harris (D) - Olubukola Ajala · Basel Bari · Joanne Liutkus · \\ Jina Hahn · Oliver Martyn · Deborah Zwicker
}

Received: February 16, 2021 / Accepted: April 20, 2021 / Published online: May 1, 2021

(C) The Author(s) 2021

\section{ABSTRACT}

Introduction: The aim of the study was to examine glycaemic control and safety of insulin degludec (degludec) in patients with either

Supplementary Information The online version contains supplementary material available at https:// doi.org/10.1007/s13300-021-01063-5.

S. B. Harris $(\square)$

Department of Family Medicine, Schulich School of Medicine and Dentistry, Western University, WCPHFM, 1465 Richmond St, London, ON N6G 2M1, Canada

e-mail: stewart.harris@schulich.uwo.ca

O. Ajala

LMC Healthcare, Alberta, Canada

B. Bari

Markham Health Plex, Markham, ON, Canada

\section{J. Liutkus}

Joanne F. Liutkus Medicine Professional

Corporation, Cambridge, ON, Canada

J. Hahn

Novo Nordisk Canada Inc., Mississauga, ON, Canada

O. Martyn

Novo Nordisk A/S, Søborg, Denmark

D. Zwicker

Division of Endocrinology and Metabolism, Department of Medicine, Dalhousie University, Halifax, Canada type 1 diabetes (T1D) or type 2 diabetes (T2D) under routine care settings in Canada.

Methods: Data were extracted from medical records of adults with T1D or T2D who switched to degludec ( \pm prandial insulin) from another basal insulin ( \pm prandial insulin) $\geq 6$ months prior to data collection. The primary endpoint was change in glycated haemoglobin $\left(\mathrm{HbA}_{1 \mathrm{c}}\right)$ at $6 \pm 3$ months after degludec initiation. Secondary endpoints included change in hypoglycaemia rate in the 6 months before versus the 6 months after switching, and change in mean total daily insulin dose.

Results: Of 667 patients assessed for eligibility, 626 were included. After $6 \pm 3$ months, $\mathrm{HbA}_{1 \mathrm{c}}$ decreased from baseline in patients with T1D $\left(-0.3 \%[-0.42,-0.14]_{95 \% \text { CI }} p<0.001\right)$ and in patients with T2D (-0.4\% [-0.55, $\left.-0.30]_{95 \% \mathrm{Cl}} ; p<0.001\right)$. In patients with T1D, there were significant reductions in the rates of overall (rate ratio [RR] 0.70), non-severe (RR 0.69 ), non-severe nocturnal (RR 0.36), and severe nocturnal hypoglycaemia (RR 0.12 ; all $p$ $\leq 0.004$ ). In patients with T2D there was a significant reduction in non-severe nocturnal hypoglycaemia (RR 0.22; $p<0.001$ ). Mean daily basal insulin dose decreased in patients with T1D (- 1.6 units $\left.[-2.8,-0.4]_{95 \% \mathrm{Cl}} ; p=0.008\right)$; there was no significant change in patients with T2D (-0.6 units $\left.[-2.7,1.4]_{95 \% \mathrm{CI}} ; p=0.543\right)$.

Conclusion: In routine clinical practice, improved glycaemic control was observed in patients with T1D or T2D switching to insulin 
degludec from other basal insulins, with either improvement or no change in hypoglycaemia rates.

Trial Registration: ClinicalTrials.gov NCT0367 4866

Keywords: Canada; Glycaemia; Glycaemic control; Hypoglycaemia; Insulin degludec; Real-world; Type 1 diabetes; Type 2 diabetes

\section{Key Summary Points}

\section{Why carry out this study?}

There are no available data on the use of and glycaemic control in patients initiating insulin degludec in clinical practice in Canada.

The aim of the study was to examine glycaemic control and safety of insulin degludec in patients with either type 1 diabetes or type 2 diabetes under routine care settings in Canada.

\section{What was learned from the study?}

In this real-world study, improved glycaemic control was observed after replacing other basal insulins with insulin degludec.

A reduction in the rate of overall, nonsevere, and nocturnal hypoglycaemia was observed in patients with type 1 diabetes initiating insulin degludec and in nonsevere nocturnal hypoglycaemia in patients with type 2 diabetes.

\section{DIGITAL FEATURES}

This article is published with digital features, including a summary slide, to facilitate understanding of the article. To view digital features for this article go to https://doi.org/10.6084/ m9.figshare.14447646.

\section{INTRODUCTION}

Insulin degludec (degludec) is a second-generation, longer-acting basal insulin with a flatter and more stable steady-state pharmacokinetic and pharmacodynamic profile compared with the first-generation basal insulin analogue, insulin glargine 100 units (U)/mL (glargine U100) [1-3]. In randomised controlled trials (RCTs), degludec was associated with a lower risk of hypoglycaemia at equivalent glycaemic control compared with glargine U100 in patients with type 2 diabetes (T2D) [4-7]. Metaanalyses of patients with type 1 diabetes (T1D) found no statistical differences were observed in the rates of overall confirmed hypoglycaemia with degludec versus glargine U100, but a lower rate of nocturnal hypoglycaemia was observed during the maintenance period with degludec $[5,7]$. However, in the RCTs SWITCH $1[8]$ and SWITCH 2 [6], degludec was associated with a reduced rate of overall symptomatic hypoglycaemia during the maintenance period compared to glargine $\mathrm{U} 100$ in T1D and T2D, respectively (SWITCH 1: rate ratio (RR) 0.89 $[0.85-0.94]_{95 \% \mathrm{CI}} ; p<0.001$ for non-inferiority, $p<0.001$ for superiority; SWITCH 2: estimated RR $\left.0.70[0.61-0.80]_{95 \% \text { CI}} ; p<0.001\right)$. Furthermore, non-inferiority of degludec versus glargine U100 for glycated haemoglobin $\left(\mathrm{HbA}_{1 \mathrm{c}}\right)$ levels was confirmed in both trials.

Degludec has also been compared with other basal insulins in clinical trial settings. For example, degludec was associated with a lower risk of nocturnal hypoglycaemia than insulin detemir (detemir) in patients with T1D [9]. In a separate study in patients with T2D, the incidence and rates of anytime confirmed hypoglycaemia were similar for degludec and insulin glargine $300 \mathrm{U} / \mathrm{mL}$ (glargine U300) during the full study period, but were higher with degludec during the titration period [10]. However, in the CONCLUDE study, there was no significant difference in the rate of overall symptomatic hypoglycaemia with insulin degludec vs glargine U300 in the maintenance period (primary endpoint), and the rates of nocturnal symptomatic and severe hypoglycaemia were nominally significantly lower with degludec during 
the maintenance period (secondary endpoints) [11].

Although RCTs are the gold standard for comparing the safety and efficacy of different therapies, they are limited by their study design and patient inclusion criteria in their ability to extrapolate to the patients seen in routine clinical practice [12]. As such, there is an increasing need for real-world evidence to assess the effectiveness of therapies in a clinical setting and in patients not selected for inclusion in RCTs.

Real-world studies investigating the effectiveness of degludec carried out in Europe demonstrated that switching to degludec from other basal insulins was associated with significantly reduced rates of hypoglycaemia and significantly lower $\mathrm{HbA}_{1 \mathrm{c}}$ compared with baseline $[13,14]$. Degludec was granted marketing authorisation in Canada in August 2017 for once-daily treatment of adults with diabetes (T1D or T2D) to improve glycaemic control [15]. According to the Canadian guidelines, degludec, glargine U100 or glargine U300 may be used in place of neutral protamine Hagedorn (NPH) for patients with T1D to reduce hypoglycaemia, and degludec alone may be used instead of detemir or glargine U100 to reduce nocturnal hypoglycaemia [16]. For patients with T2D treated with basal insulin for whom a lower risk of hypoglycaemia is a priority, degludec, glargine U100, glargine U300 or detemir should be considered over NPH insulin to reduce the risk of nocturnal and symptomatic hypoglycaemia [17]. Degludec may be considered over glargine U100 to reduce overall and nocturnal hypoglycaemia, and severe hypoglycaemia in patients at high cardiovascular risk. The guidelines recommend insulin initiation of $10 \mathrm{U}$ once-daily at bedtime, and titration to a target fasting blood glucose of 4.0-7.0 mmol/L or individualised targets [18]. Degludec should be titrated by $2 \mathrm{U}$ every 3-4 days or $4 \mathrm{U}$ once a week [18].

There are no available data on the use and effectiveness of degludec under routine care in Canada. The objective of the present study was to evaluate the clinical effectiveness of switching basal insulin to degludec in insulin-treated patients with either T1D or T2D, under conditions of routine clinical care in Canada. A secondary objective was to investigate the use of degludec in a real-world setting, including reasons for discontinuation of treatment.

\section{METHODS}

\section{Study Design and Population}

This was a multicentre, retrospective, non-interventional chart review study (ClinicalTrials.gov, NCT03674866) in which medical record data were collected from 38 sites across five Canadian provinces, from 29 October 2018 (first patient first visit) to 26 April 2019 (last patient last visit). Sites were pre-identified by IQVIA Solutions Canada Inc. and Novo Nordisk Canada Inc. and were invited to participate in the study. Those sites that expressed an interest in participating were asked to complete a feasibility questionnaire (Table S1 in the Supplementary Material). Sites were randomly selected on the basis of their ability to enrol approximately 15 patients who were treated with degludec (degludec U100 or degludec U200 $\left(\right.$ FlexTouch $\left.{ }^{\circledR}\right)$ ). At the time of study, these treatments were available in Canada and were relatively new. Therefore, participating sites were mostly specialist and patients were likely to have private access to degludec. Inclusion of patients in the study started with the most recent patient treated with degludec who attended the clinic and then worked backwards, until all eligible patients were invited.

The study consisted of a baseline period, defined as the most recent recording before initiating degludec ( $\leq 3$ months before initiation); and a follow-up period, defined as a recording $6 \pm 3$ months after switching basal insulin to degludec (see Fig. S1 in the Supplementary Material). Eligible patients were adults ( $\geq 18$ years of age at the time of degludec initiation) with a diagnosis of T1D or T2D who had been switched to degludec (with or without prandial insulin) from another basal insulin (with or without prandial insulin) at least 6 months prior to data collection. Patients were required to have been treated with another basal insulin for at least 6 months prior to the 
switch to degludec and have at least one documented medical visit within the first $6 \pm 3$ months after switching. The minimum data required for patients included age, diabetes type, $\mathrm{HbA}_{1 \mathrm{c}}$, duration of diabetes, duration and type of insulin treatment, at least 12 months of medical follow up at the study site and an estimated glomerular filtration rate (eGFR) measurement within the last $12 \pm 6$ months.

Exclusion criteria included treatment with subcutaneous insulin infusion (insulin pump therapy) or pre-mix insulin within 6 months prior to degludec initiation, previous participation in this study (defined as signed informed consent) and initiation of degludec outside of routine clinical practice (e.g. a clinical trial).

This study was performed in accordance with the Declaration of Helsinki [19] and Good Pharmacoepidemiology Practice. The protocol and patient consent forms were approved by research ethics boards/institutional review boards for all sites. A full list of the research ethics boards/institutional review boards, with their reference numbers, is provided in Table S2 in the Supplementary Material. Informed consent was obtained from all participants prior to data collection.

\section{Outcome Measures}

The objectives of this study were to describe glycaemic control, rates of hypoglycaemia, number and dose of insulin and of non-insulin glucose-lowering drugs, before and after initiation of degludec. A further objective was to describe degludec use in a real-world Canadian setting, including reasons for initiating and discontinuing degludec.

The primary endpoint was change in $\mathrm{HbA}_{1 \mathrm{c}}$ from baseline to 6 months after degludec initiation. Secondary endpoints included change in fasting plasma glucose (FPG) from baseline to $6 \pm 3$ months; change in the proportion of patients achieving $\mathrm{HbA}_{1 \mathrm{c}}$ targets $<7.0 \%$, $<7.5 \%$, and $<8.0 \%$ from baseline to $6 \pm 3$ months; and change in hypoglycaemia rate between the 6 -month period before initiating degludec and the 6-month period after initiating degludec. Other secondary endpoints were the changes in mean daily insulin doses (total, basal, prandial) and body weight from baseline to 6 months. Study endpoints were assessed at baseline and after initiating degludec, with the exception of hypoglycaemia endpoints, which were assessed over the 6-month period prior to degludec initiation and the 6-month period after degludec initiation.

Events were defined as hypoglycaemic if they were documented as such in the medical records by the treating physician or an appropriately trained delegate. Severe hypoglycaemia was defined as a reported event requiring the assistance of another person to actively administer carbohydrate, glucagon or take other corrective actions [20]. Nocturnal hypoglycaemia was defined as any event in which the words 'nocturnal' or 'night' (or their equivalent in the local language) were used in the patient medical records. Hypoglycaemia categories included overall (all events), non-severe (all events with the exception of severe events), non-severe nocturnal (nocturnal events with the exception of severe nocturnal events), severe and severe nocturnal (events that were categorised as severe and nocturnal).

\section{Statistical Analysis}

The full analysis set (FAS) includes all patients who met inclusion/exclusion criteria and signed the informed consent form. Analyses were conducted separately for patients with T1D and those with T2D. Baseline demographic and clinical characteristics are reported for patients using descriptive statistics.

The primary endpoint was analysed using a paired $t$ test, as a two-sided test with a significance level of $p<0.05$. In addition, the primary endpoint was analysed as a baseline-adjusted change using an analysis of covariance (ANCOVA) model. In the ANCOVA model, change from baseline in $\mathrm{HbA}_{1 \mathrm{c}}$ was modelled as a function of the baseline value and following relevant covariates: age; body mass index (BMI); gender; diabetes duration; duration of insulin therapy; type of basal insulin; at least one hypoglycaemic risk factor (only patients with T2D) and $\mathrm{HbA}_{1 \mathrm{c}}$ at baseline. Those relevant 
Table 1 Demographic and clinical characteristics at baseline in patients with T1D or T2D

\begin{tabular}{|c|c|c|}
\hline & $\begin{array}{l}\text { T1D } \\
(n=275)\end{array}$ & $\begin{array}{l}\text { T2D } \\
(n=351)\end{array}$ \\
\hline \multirow[t]{2}{*}{ Male } & $168(61.1)$ & $210(59.8)$ \\
\hline & {$[0(0)]$} & {$[0(0)]$} \\
\hline \multirow[t]{2}{*}{ Age, years } & $47.7 \pm 14.1$ & $60.7 \pm 10.1$ \\
\hline & {$[0(0)]$} & {$[0(0)]$} \\
\hline \multirow[t]{2}{*}{ BMI, $\mathrm{kg} / \mathrm{m}^{2}$} & $27.9 \pm 5.6$ & $32.4 \pm 6.8$ \\
\hline & {$[43(15.64)]$} & {$[43(12.25)]$} \\
\hline $\mathrm{HbA}_{1 \mathrm{c}}, \%$ & $8.3 \pm 1.5$ & $8.3 \pm 1.3$ \\
\hline \multirow[t]{2}{*}{$\mathrm{mmol} / \mathrm{mol}$} & $67.2 \pm 16.4$ & $67.2 \pm 14.2$ \\
\hline & {$[0(0)]$} & {$[0(0)]$} \\
\hline \multirow[t]{2}{*}{$\mathrm{FPG}, \mathrm{mmol} / \mathrm{L}$} & $9.8 \pm 3.8$ & $9.1 \pm 4.2$ \\
\hline & {$[117(42.55)]$} & {$[115(32.76)]$} \\
\hline \multirow[t]{2}{*}{ Time since diabetes diagnosis, years } & $24.2 \pm 14.4$ & $17.0 \pm 8.6$ \\
\hline & {$[0(0)]$} & {$[0(0)]$} \\
\hline \multirow[t]{2}{*}{ Time since initiation of insulin therapy, years } & $23.4 \pm 14.9$ & $7.6 \pm 5.7$ \\
\hline & {$[0(0)]$} & {$[0(0)]$} \\
\hline \multicolumn{3}{|l|}{ Basal insulin therapy } \\
\hline \multirow[t]{2}{*}{ Basal insulin, injections per day } & $1.2(0.4)$ & $1.2(0.4)$ \\
\hline & {$[0(0)]$} & {$[0(0)]$} \\
\hline \multirow[t]{2}{*}{ Total basal insulin, units per day } & $30.9(19.7)$ & $51.8(39.2)$ \\
\hline & {$[4(1.5)]$} & {$[0(0)]$} \\
\hline None & $0(0)$ & $0(0)$ \\
\hline $\mathrm{NPH}$ insulin $\left(\right.$ Humulin $\left.^{\circledR} \mathrm{N}\right)$ & $3(1.1)$ & $9(2.6)$ \\
\hline $\mathrm{NPH}$ insulin $\left(\right.$ Novolin $^{\circledR}$ GE NPH) & $3(1.1)$ & $8(2.3)$ \\
\hline Insulin detemir 100 units $/ \mathrm{mL}\left(\right.$ Levemir $\left.^{\circledR}\right)$ & $60(21.8)$ & $92(26.2)$ \\
\hline Insulin glargine 100 units/mL (Lantus ${ }^{\circledR}$ ) & $131(47.6)$ & $159(45.3)$ \\
\hline Insulin glargine 300 units $/ \mathrm{mL}\left(\right.$ Toujeo $\left.^{\circledR}\right)$ & $74(26.9)$ & $74(21.1)$ \\
\hline Insulin glargine 100 units/mL (Basaglar ${ }^{\circledR}$ ) & $4(1.5)$ & $9(2.6)$ \\
\hline Other & $0(0)$ & $0(0)$ \\
\hline Unknown & $0(0)$ & $0(0)$ \\
\hline
\end{tabular}


Table 1 continued

T1D

T2D

$(n=275)$

$(n=351)$

Basal insulin injections

Once daily

$207(75.3)$

$285(81.2)$

Twice daily

$68(24.7)$

$65(18.5)$

More than twice daily

$0(0)$

$1(0.3)$

Prandial insulin therapy

Prandial insulin, injections per day

$3.0 \pm 0.3$

$2.8 \pm 0.6$

Total prandial insulin, units per day

[22 (8.0)]

[133 (37.9)]

$29.5 \pm 16.9$

$53.9 \pm 42.9$

[33 (12.0)]

[136 (38.7)]

None

$8(3.0)$

$124(35.9)$

Rapid-acting insulin analogues

$238(88.1)$

$205(59.4)$

Short-acting insulins

$24(8.9)$

$16(4.6)$

Insulin pump

$0(0)$

$0(0)$

Unknown

$5(1.8)$

$6(1.7)$

Total insulin dose, units per day

$59.9(32.4)$

$85.9(68.7)$

Non-insulin glucose-lowering medications

Number per patient

$0.3 \pm 0.6$

$2.1 \pm 1.2$

[2(0.7)]

[1 (0.3)]

None

$219(80.2)$

41 (11.7)

Glucagon-like peptide 1

$9(3.3)$

$108(30.9)$

Dipeptidyl peptidase-4 inhibitor

$4(1.5)$

$103(29.4)$

Sodium-glucose cotransporter 2 inhibitor

$26(9.5)$

$194(55.4)$

Metformin

31 (11.4)

255 (72.9)

Sulfonylurea

$2(0.7)$

$51(14.6)$

Thiazolidinedione

$0(0)$

$6(1.7)$

Alpha-glucosidase inhibitors (acarbose)

$0(0)$

$3(0.9)$

Meglitinide

$0(0)$

$3(0.9)$

Unknown

$2(0.7)$

$1(0.3)$

Other

$0(0)$

$2(0.6)$

Data are mean \pm standard deviation or $n(\%)$, with the $n$ (\%) missing for an endpoint reported in square brackets $H b A_{1 c}$ glycated haemoglobin, $B M I$ body mass index, $F P G$ fasting plasma glucose, $N$ number of patients, $N P H$ neutral protamine Hagedorn, TID type 1 diabetes, T2D type 2 diabetes 
A

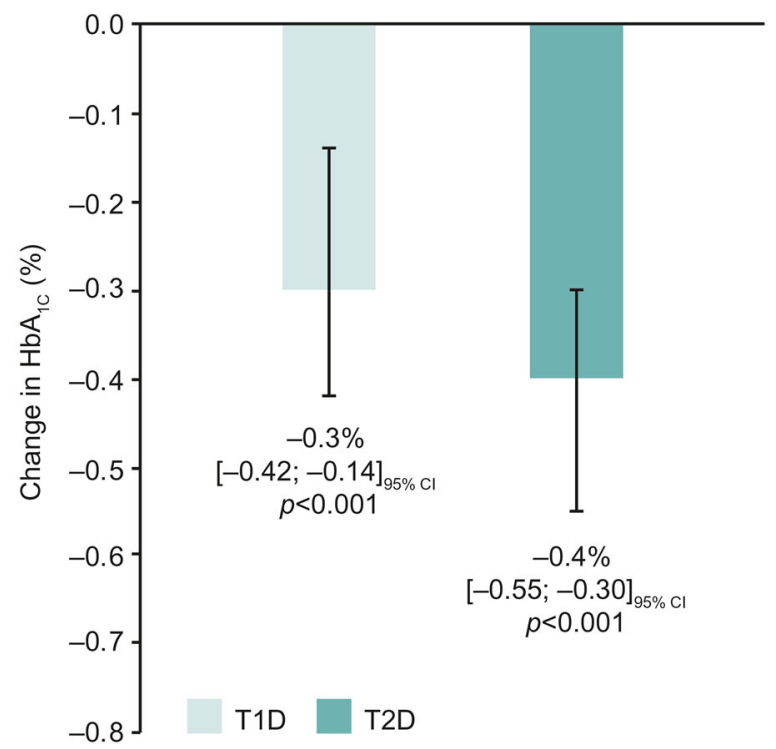

Fig. 1 Change from baseline to $6 \pm 3$ months after initiating degludec in $\mathrm{HbA}_{1 \mathrm{c}}(\mathbf{a})$ and FPG (b). $P$ values were determined using a paired $t$ test. Data are mean (95\% CI) values based on a paired $t$ test comparing observed data at baseline and 6 months. Only patients

covariates with a significance level $<0.20$ in individual ANCOVA models were included in the global ANCOVA model. Only those variables with a $p$ value $<0.10$ in the global ANCOVA were maintained in the final model. Changes in FPG, insulin dose and body weight were analysed using paired $t$ tests, the change in proportion of patients attaining $\mathrm{HbA}_{1 \mathrm{c}}$ targets was analysed using McNemar's test, and the change in rate of hypoglycaemic episodes was analysed using a negative binomial model (for further information, see Supplementary Material).

Missing data were not imputed and there were no adjustments for multiple comparisons. All statistical analyses were performed using SAS 9.4 (SAS Institute, Cary, NC).

\section{RESULTS}

\section{Study Population Demographics and Clinical Characteristics}

In total, 667 patients were assessed for eligibility, of whom 626 met the study inclusion
B

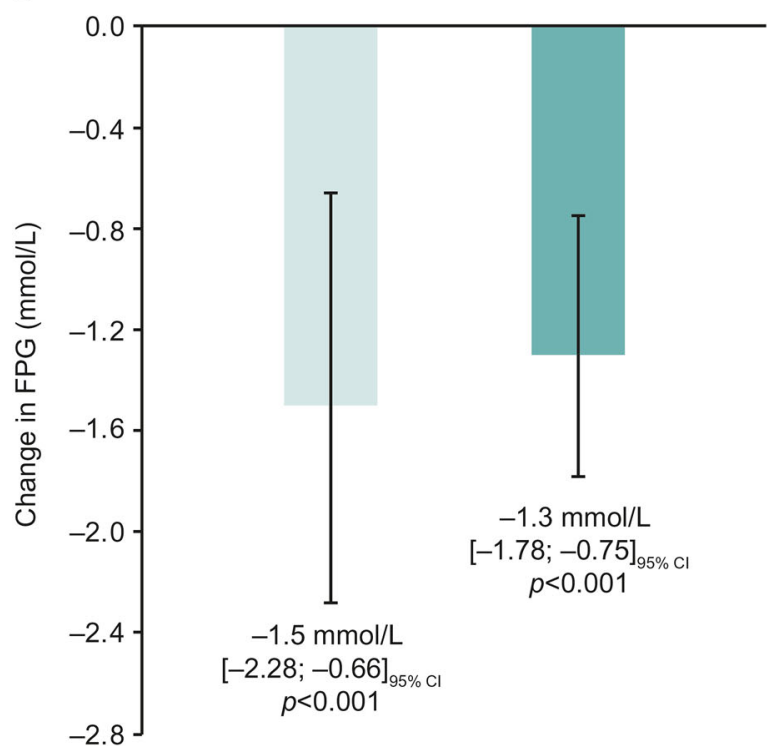

with data at baseline and $6 \pm 3$ months after degludec initiation were included in the analysis. $H b A_{1 \mathrm{c}}$ glycated haemoglobin, $C I$ confidence interval, $F P G$ fasting plasma glucose, $T 1 D$ type 1 diabetes, $T 2 D$ type 2 diabetes

criteria and made up the FAS (reasons for screening failure are presented in Table S3 in the Supplementary Material). Of these, 275 (43.9\%) had a diagnosis of T1D and 351 patients of T2D (56.1\%). The demographic and clinical characteristics of patients at baseline are presented in Table 1.

Of patients with T1D, the mean (standard deviation [SD]) age was 47.7 (14.1) years, duration of diabetes was 24.2 (14.4) years and duration since insulin initiation was 23.4 (14.9) years. The majority of patients with T1D were receiving once-daily basal insulin injections $(n=207,75.3 \%)$, while nearly all patients also received prandial insulin (only $n=8,3.0 \%$ of patients did not receive prandial insulin [prandial insulin was unknown for $n=5,1.8 \%$ of patients]). The most common comorbidities were dyslipidaemia $(45.7 \%)$ and hypertension (31.1\%; Table S4).

Of patients with $\mathrm{T} 2 \mathrm{D}$, the mean (SD) age was 60.7 (10.1) years, duration of diabetes was 17.0 (8.6) years and duration since insulin initiation was 7.6 (5.7) years. The majority of patients with T2D were treated with once-daily basal 


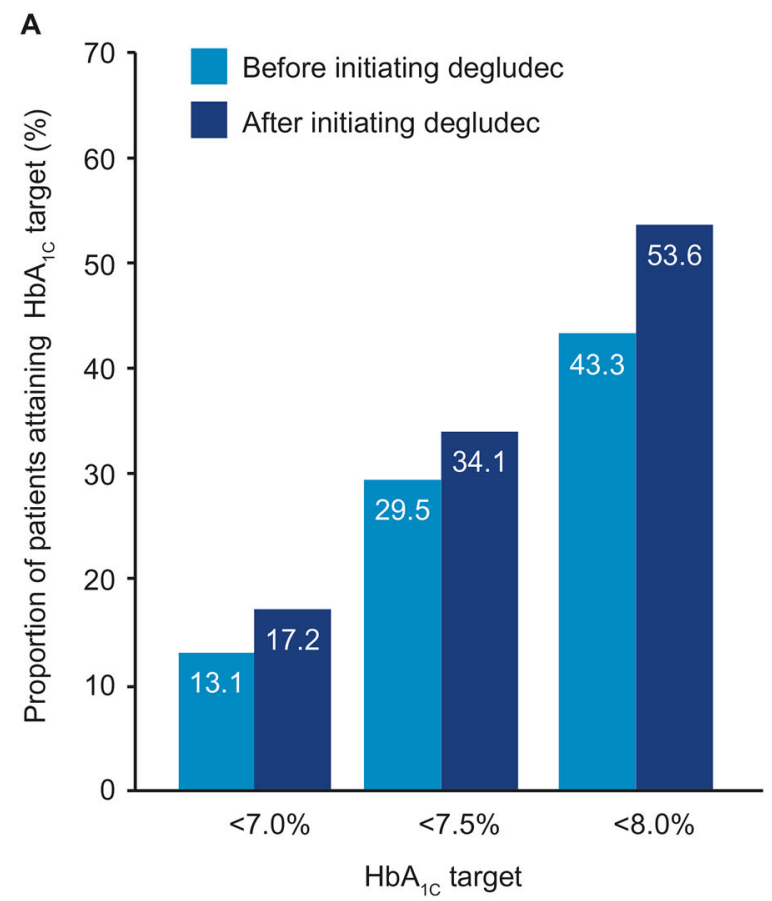

Fig. 2 Proportion of patients achieving $\mathrm{HbA}_{1 \mathrm{c}}$ targets at baseline and $6 \pm 3$ months after initiating degludec in T1D (a) and T2D (b). Baseline refers to the most recent measurement prior to initiating degludec ( $>3$ months prior to switch). After initiating degludec refers to the

insulin injections $(n=285,81.2 \%)$, and twothirds of patients received prandial insulin injections $(n=124,35.9 \%$ of patients did not receive prandial insulin). The most common comorbidities were hypertension (63.1\%) and dyslipidaemia (72.9\%; Table S4).

\section{Glycaemic Control}

After $6 \pm 3$ months of treatment with degludec, $\mathrm{HbA}_{1 \mathrm{c}}$ was significantly lower compared with baseline in patients with T1D $(-0.3 \%[-0.42$, $\left.-0.14]_{95 \%(\mathrm{CI})} ; p<0.001\right)$ and in patients with T2D $\left(-0.4 \%[-0.55,-0.30]_{95 \% \text { Cl}} ; p<0.001\right.$; Fig. 1a). FPG was significantly reduced after $6 \pm 3$ months compared with baseline (T1D: $-1.5 \mathrm{mmol} / \mathrm{L} \quad[-2.28,-0.66]_{95 \% \mathrm{CI}} ; \mathrm{T} 2 \mathrm{D}$ : $-1.3 \mathrm{mmol} / \mathrm{L}[-1.78,-0.75]_{95 \% \mathrm{CI}} ; p<0.001$ for both; Fig. 1b). In both T1D and T2D, among patients who had an $\mathrm{HbA}_{1 \mathrm{c}}$ value available at baseline and at $6 \pm 3$ months, there was a

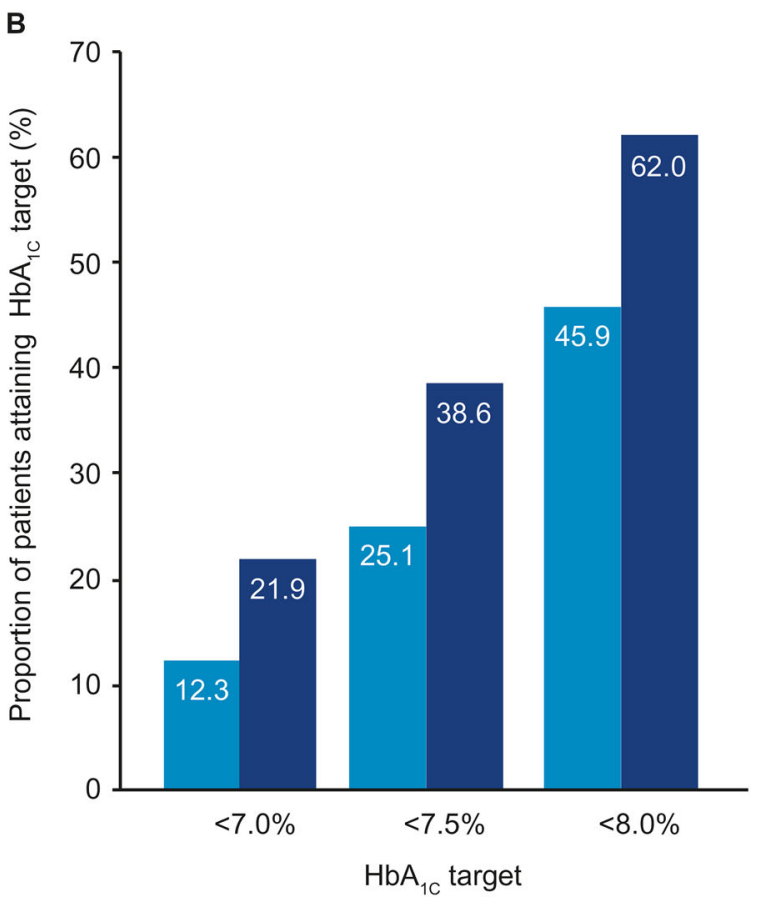

period between 0 and 6 months after initiating degludec. None of the comparisons presented were statistically significant. $H b A_{1 \mathrm{c}}$ glycated haemoglobin, TID type 1 diabetes, $T 2 D$ type 2 diabetes

significantly greater proportion of patients with $\mathrm{HbA}_{1 \mathrm{c}}$ above $8.0 \%$ at baseline who subsequently achieved this target $(<8.0 \%)$ at $6 \pm 3$ months, compared with the proportion of patients with $\mathrm{HbA}_{1 \mathrm{c}}$ below $8.0 \%$ at baseline who then had an $\mathrm{HbA}_{1 \mathrm{c}}$ above target at 6 months $(\geq 8.0 \%$; $p<0.001$ for both; Table S5). In T2D, there was a significantly greater proportion of patients with $\mathrm{HbA}_{1 \mathrm{c}}$ above target at baseline who subsequently achieved target at $6 \pm 3$ months when using both $\mathrm{HbA}_{1 \mathrm{c}}$ targets of $<7.0 \%$ $(p<0.001)$ and $<7.5 \%(p<0.001)$; however, these changes were not significant for patients with T1D (Table S5). There were numerically greater proportions of patients achieving $\mathrm{HbA}_{1 \mathrm{c}}$ targets of $<7.0 \%,<7.5 \%$, and $<8.0 \%$ at $6 \pm 3$ months compared with baseline for patients with T1D (Fig. 2a) and T2D (Fig. 2b), although statistical significance was not observed. 
A

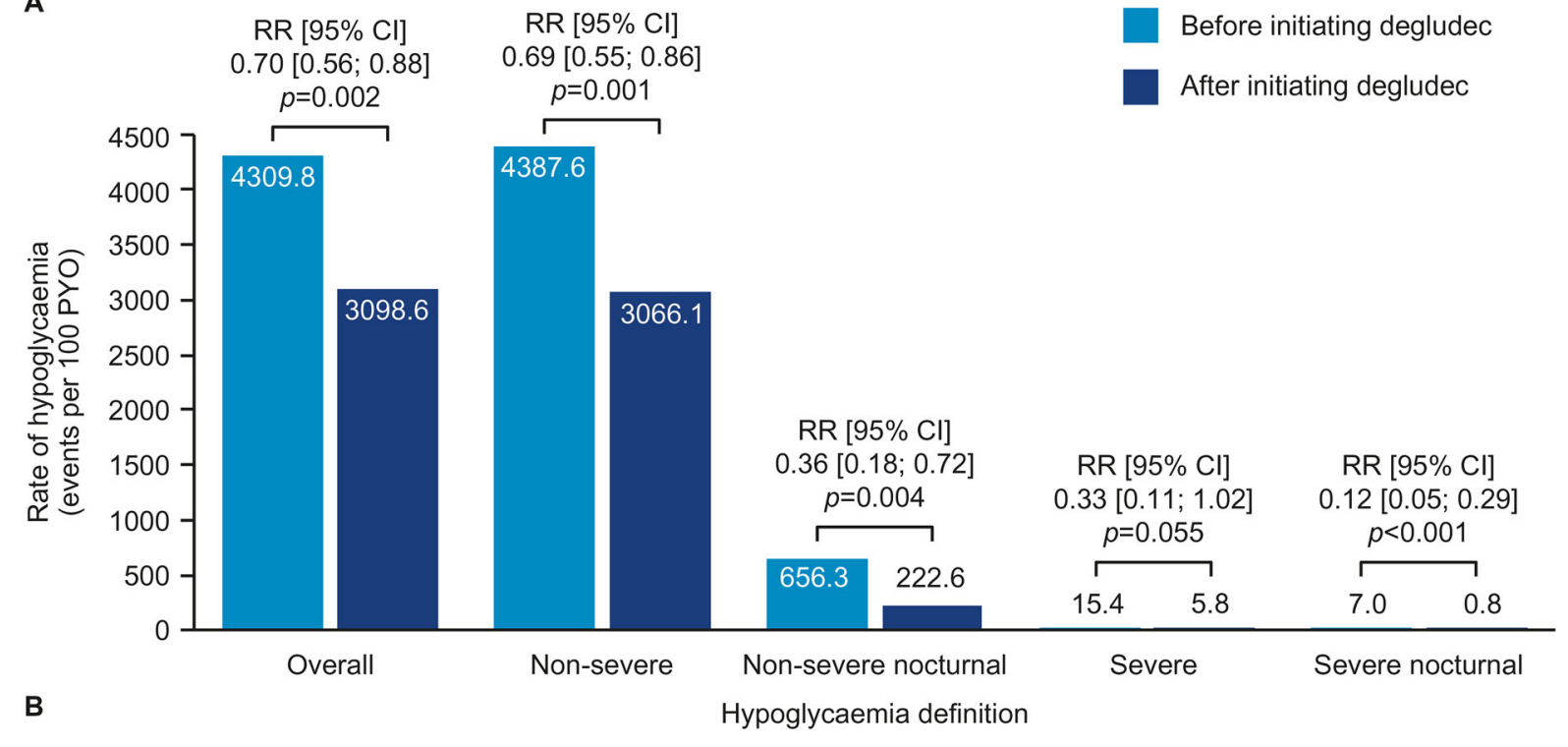

$\mathrm{RR}[95 \% \mathrm{Cl}]$

0.69 [0.55; 0.86]

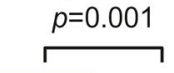

4387.6

B

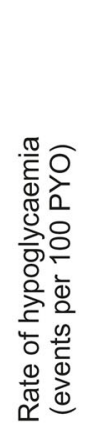

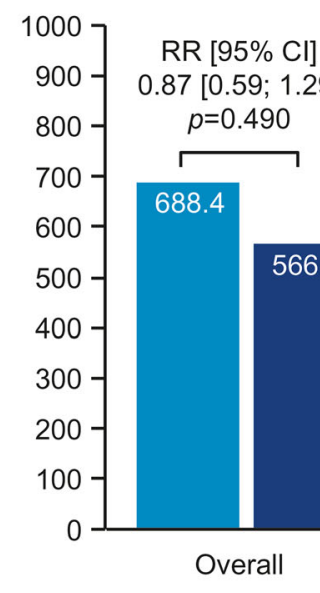

Before initiating degludec

After initiating degludec

Hypoglycaemia definition 
In patients with $\mathrm{T} 2 \mathrm{D}$, a significant reduction in the rate of non-severe nocturnal hypoglycaemia was observed compared with baseline after switching (RR $0.22\left[\begin{array}{lll}0.12, & 0.43\end{array}\right]_{95 \% \mathrm{Cl}}$; $p<0.001$; Fig. 3b). There were numerically lower rates of overall hypoglycaemia, overall non-severe hypoglycaemia, severe hypoglycaemia, and severe nocturnal hypoglycaemia after switching to degludec (Fig. 3b).

\section{Insulin Dose}

In patients with $\mathrm{T} 1 \mathrm{D}$, there was a statistically significant decrease in mean (SD) daily basal insulin dose from 30.9 (19.7) $\mathrm{U}$ at baseline to 29.3 (18.2) $\mathrm{U}$ at $6 \pm 3$ months (difference $\left.-1.6 \mathrm{U}[-2.8,-0.4]_{95 \% \mathrm{Cl}} ; p=0.008\right)$, and in mean (SD) daily prandial insulin, from 29.5 (16.9) U to $28.0(18.3) \mathrm{U}$, respectively (difference $\left.-1.2 \mathrm{U}[-2.36,-0.10]_{95 \% \mathrm{CI}} ; p=0.033\right)$. In patients with $\mathrm{T} 2 \mathrm{D}$, there was no change in the mean (SD) daily basal insulin dose (baseline, 51.8 [39.2] U; $6 \pm 3$ months, 51.2 [35.6] U; difference $\left.-0.6 \mathrm{U}[-2.7,1.4]_{95 \% \mathrm{CI}} ; p=0.543\right)$ or in the mean (SD) daily prandial insulin (baseline, 53.9 [42.9] U; $6 \pm 3$ months, 53.1 [54.7] U; difference $\left.0.0 \mathrm{U}[-5.11,5.16]_{95 \% \mathrm{CI}} ; p=0.992\right)$. Mean (SD) total daily insulin dose at $6 \pm 3$ months was $57.3 \quad(32.1)$ and 84.7 (72.5) U/day for T1D and T2D, respectively.

\section{Body Weight}

In patients with T1D, there was a small but significant increase in body weight at $6 \pm 3$ months of degludec treatment compared with baseline $\left(0.5 \mathrm{~kg} \quad[0.13,0.97]_{95 \% \mathrm{Cl}}\right.$; $p=0.011$ ). In patients with $\mathrm{T} 2 \mathrm{D}$, there was no significant difference between body weight at baseline and at $6 \pm 3$ months $(0.3 \mathrm{~kg}[-0.16$, $\left.0.68]_{95 \% \mathrm{CI}} ; p=0.217\right)$.

\section{Use of Degludec in a Real-World Setting}

Physicians' reasons for initiating degludec in patients with T1D or T2D are summarised in Table S6. The most common reason for initiating patients on degludec was patients not achieving their glycaemic target (T1D: 174 patients [68.8\%]; T2D: 248 patients [73.4\%]), followed by reasons of hypoglycaemia (T1D: 135 patients [53.4\%]; T2D: 111 patients [32.8\%]) and variability in fasting blood glucose (T1D: 112 patients [44.3\%]; T2D: 83 patients [24.6\%]). Of the patients who were switched to degludec because of hypoglycaemia, the most common reason was non-severe hypoglycaemia (T1D: 116 patients [85.9\%]; T2D: 91 patients [82.0\%]), followed by nocturnal (T1D: 58 patients [43.0\%]; T2D: 48 patients [43.2\%]) and then severe hypoglycaemia (T1D: 12 patients [8.9\%]; T2D: 6 patients [5.4\%]). Five patients $(1.8 \%)$ with T1D and three patients $(0.9 \%)$ with T2D discontinued degludec during the study period. Physicians' reasons for discontinuation are summarised in Table S7. Of the patients with known reasons, one patient with T1D discontinued degludec because of a device issue and two patients with T2D discontinued because of the cost of insulin.

\section{DISCUSSION}

In this real-world study in patients with T1D or T2D, improved glycaemic control (in terms of both $\mathrm{HbA}_{1 \mathrm{c}}$ and FPG) without any penalty regarding hypoglycaemia was observed in patients in the 6 months after switching to degludec compared with the 6-month period prior to degludec initiation, under usual clinical care settings. Compared with the pre-switch period, patients with T1D had significantly reduced rates of overall, non-severe hypoglycaemia and nocturnal hypoglycaemia (both severe and non-severe), whereas those with T2D had a statistically significant reduction in nonsevere nocturnal hypoglycaemia. In this study, the majority of patients were taking insulin glargine U100 ( 45\%), insulin glargine U300 ( $\sim 20-25 \%)$ or detemir $(\sim 20-25 \%)$ before switching. The results of the study therefore provide data on the impact of switching to degludec in a real-life clinical setting, and add to the body of evidence from RCTs evaluating degludec versus specific basal insulins $[6,8]$.

The improvements in glycaemic control in the current study were similar to those reported in EU-TREAT (European TREsiba AudiT), a study 
of similar design conducted in 96 sites across six European countries [13]. EU-TREAT included patients with T1D $(n=1717)$ and T2D $(n=833)$. After 6 months, $\mathrm{HbA}_{1 \mathrm{c}}$ was reduced versus baseline by $-0.20 \% \quad[-0.24$, $-0.17]_{95 \% \text { CI }}$ in patients with T1D and $-0.51 \%$ $[-0.58,-0.43]_{95 \% \mathrm{CI}}$ in patients with T2D. However, in EU-TREAT there was a significant reduction in the rate of overall hypoglycaemia in both patients with T1D and T2D [13], whereas in the current study this was only observed for patients with T1D. There are several potential reasons for this difference in results. Firstly, there was a larger proportion of patients with T2D in our study who were also receiving sodium-glucose cotransporter 2 inhibitors and glucagon-like peptide 1 receptor agonist treatment at baseline and use of these agents may have mitigated hypoglycaemic episodes. Secondly, the sample size of the current study was smaller than that of EU-TREAT (T1D, $n=275$; T2D, $n=351$ vs T1D, $n=1717$; T2D, $n=833$ ). The lack of statistical significance in the rate reduction of overall hypoglycaemia in patients with T2D in the current study may be a result of the small number of patients, and therefore of hypoglycaemic events. Thirdly, the reporting of hypoglycaemia was likely to have been different between sites involved in the CAN-TREAT and those in the EU-TREAT.

As with all retrospective studies, there were limitations to CAN-TREAT. As expected, some data were missing in this retrospective chart review. The retrospective nature of this analysis may have influenced the reported incidence, and the latter was probably affected by differences in the study sites. This is consistent with results from the observational, global, Hypoglycaemia Assessment Tool (HAT) study, which documented regional differences in hypoglycaemia rates [21]. Also, in the HAT study, rates of any and severe hypoglycaemia reported from retrospective periods were lower than those from prospective periods, suggesting that under-reporting is common. Similarly, results from the real-world InHypo-DM study in Canada suggested that the incidence of hypoglycaemia among adults with diabetes taking insulin and/or insulin secretagogues was higher than previously thought from clinical trials
[22]. Another large observational study, based in Europe, has also documented that non-severe hypoglycaemia in particular is likely to be under-reported [23]. In the current study, since patients were more likely to be closely monitored after switching, a greater number of hypoglycaemic episodes were expected during the post-switch period. This implies that the observed reduction in the number of hypoglycaemic episodes might have been underestimated. As degludec was relatively new in Canada at the time of the study, participating sites were mostly specialist centres, and the majority of patients included were those with private access to degludec and were likely to receive guideline-recommended optimal therapy. Therefore, the study patient population may differ from the general population in Canada. Another limitation of the current study was the lack of a direct comparator arm.

Strengths of the study included the relatively broad inclusion and exclusion criteria and noninterventional design of the study, which reflects the day-to-day experience of patients and healthcare providers when switching to degludec in real-world settings. Also, the fact that patients switched to degludec well before clinicians were aware of the retrospective study would be conducted lends credibility to the findings.

\section{CONCLUSIONS}

Patients with either T1D or T2D switching from another basal insulin to degludec in routine practice settings in Canada achieved improved glycaemic control, as measured 6 months after switching when compared with the 6 months prior to switching. After switching, there was also an improvement in the rate of overall, nonsevere and nocturnal hypoglycaemia in patients with T1D and in non-severe nocturnal hypoglycaemia in patients with T2D.

\section{ACKNOWLEDGEMENTS}

The authors would like to thank the participants of the study. 
Funding. Sponsorship for this analysis and the journal's Rapid Service Fee were funded by Novo Nordisk A/S. Site investigators gathered the data, and the sponsor performed site monitoring, collected the data, and performed the analyses.

Medical Writing Assistance. Medical writing support for the development of this manuscript, under the direction of the authors, was provided by Matthew Robinson, PhD, of Ashfield MedComms, an Ashfield Health company, and funded by Novo Nordisk.

Authorship. All named authors meet the International Committee of Medical Journal Editors (ICMJE) criteria for authorship for this article, take responsibility for the integrity of the work as a whole, and have given their approval for this version to be published.

Authors' Contributions. Stewart B. Harris is the guarantor of this work and, as such, had full access to all the data in the study, and takes responsibility for the integrity of the data and the accuracy of the data analysis. Stewart B. Harris, Olubukola Ajala, Basel Bari, Joanne Liutkus, and Deborah Zwicker were investigators. All authors contributed to critical analysis and interpretation of the data, drafting and/or critically revising the article and sharing in the final responsibility for the content of the manuscript, as well as the decision to submit it for publication.

List of Investigators. The full list of site investigators is presented in Table S2 in the Supplementary Material.

Disclosures. Stewart B. Harris has received fees as a consultant for AstraZeneca, Boehringer Ingelheim, Eli Lilly, Janssen, Medtronic, Merck \& Co, Novo Nordisk, and Sanofi; for research support for the Juvenile Diabetes Research Foundation, the Canadian Institutes of Health Research, the Lawson Foundation, Novo Nordisk, Sanofi, AstraZeneca, and Health Canada/ First Nations and Inuit Health Branch; and as an advisory board member for the Juvenile Diabetes Research Foundation, the Canadian
Institutes of Health Research, the Lawson Foundation, Novo Nordisk, Sanofi, AstraZeneca, and Health Canada/First Nations and Inuit Health Branch. Olubukola Ajala has received funding for clinical trials from Novo Nordisk and has presented educational data to other healthcare professionals on behalf of Novo Nordisk. Basel Bari has participated in regional and national advisory boards for Novo Nordisk, Sanofi, AstraZeneca, Boehringer Ingelheim, Lilly; received honoraria for speaking engagements from Novo Nordisk, Sanofi, AstraZeneca, Boehringer Ingelheim, Lilly, Janssen, and Merck. Joanne Liutkus receives funding for clinical trials from Novo Nordisk; participates in advisory boards and acts as a consultant in the preparation of educational materials; presenter of educational data to other health professionals on behalf of Novo Nordisk. Jina Hahn and Oliver Martyn are employees of, and own shares in, Novo Nordisk. Deborah Zwicker has received funding for clinical trial from Novo Nordisk and Sanofi; has received fees as an advisory board member or as an educational presenter for Abbott, AstraZeneca, Boehringer Ingelheim, Jansen, Lilly, Medtronic, Merck, Novo Nordisk, and Sanofi.

Compliance with Ethics Guidelines. This study was performed in accordance with the Declaration of Helsinki and Good Pharmacoepidemiology Practice. The protocol and patient consent forms were approved by research ethics boards/institutional review boards for all sites. A full list of the research ethics boards/institutional review boards, with their reference numbers, is provided in Table S2 in the Supplementary Material. Informed consent was obtained from all participants prior to data collection.

Data Availability. The datasets generated and/or analysed during the current study are available from the corresponding author on reasonable request.

Open Access. This article is licensed under a Creative Commons Attribution-NonCommercial 4.0 International License, which permits any non-commercial use, sharing, adaptation, 
distribution and reproduction in any medium or format, as long as you give appropriate credit to the original author(s) and the source, provide a link to the Creative Commons licence, and indicate if changes were made. The images or other third party material in this article are included in the article's Creative Commons licence, unless indicated otherwise in a credit line to the material. If material is not included in the article's Creative Commons licence and your intended use is not permitted by statutory regulation or exceeds the permitted use, you will need to obtain permission directly from the copyright holder. To view a copy of this licence, visit http://creativecommons.org/licenses/bync/4.0/.

\section{REFERENCES}

1. Heise T, Hovelmann U, Nosek L, Hermanski L, Bottcher SG, Haahr H. Comparison of the pharmacokinetic and pharmacodynamic profiles of insulin degludec and insulin glargine. Expert Opin Drug Metab Toxicol. 2015;11:1193-201.

2. Heise T, Nosek L, Bottcher SG, Hastrup H, Haahr H. Ultra-long-acting insulin degludec has a flat and stable glucose-lowering effect in type 2 diabetes. Diabetes Obes Metab. 2012;14:944-50.

3. Heise T, Hermanski L, Nosek L, Feldman A, Rasmussen S, Haahr H. Insulin degludec: four times lower pharmacodynamic variability than insulin glargine under steady-state conditions in type 1 diabetes. Diabetes Obes Metab. 2012;14:859-64.

4. Marso SP, McGuire DK, Zinman B, et al. Efficacy and safety of degludec versus glargine in type 2 diabetes. N Engl J Med. 2017;377:723-32.

5. Vora J, Christensen T, Rana A, Bain SC. Insulin degludec versus insulin glargine in type 1 and type 2 diabetes mellitus: a meta-analysis of endpoints in phase 3a trials. Diabetes Ther. 2014;5:435-46.

6. Wysham C, Bhargava A, Chaykin L, et al. Effect of insulin degludec vs insulin glargine U100 on hypoglycemia in patients with type 2 diabetes: the SWITCH 2 randomized clinical trial. JAMA. 2017;318:45-56.

7. Ratner RE, Gough SC, Mathieu C, et al. Hypoglycaemia risk with insulin degludec compared with insulin glargine in type 2 and type 1 diabetes: a pre- planned meta-analysis of phase 3 trials. Diabetes Obes Metab. 2013;15:175-84.

8. Lane W, Bailey TS, Gerety G, et al. Effect of insulin degludec vs insulin glargine U100 on hypoglycemia in patients with type 1 diabetes: the SWITCH 1 randomized clinical trial. JAMA. 2017;318:33-44.

9. Davies M, Sasaki T, Gross JL, et al. Comparison of insulin degludec with insulin detemir in type 1 diabetes: a 1-year treat-to-target trial. Diabetes Obes Metab. 2016;18:96-9.

10. Rosenstock J, Cheng A, Ritzel R, et al. More similarities than differences testing insulin glargine 300 Units/mL versus insulin degludec 100 Units/mL in insulin-naive type 2 diabetes: the randomized headto-head BRIGHT trial. Diabetes Care. 2018. https:// doi.org/10.2337/dc18-0559.

11. Philis-Tsimikas A, Klonoff DC, Khunti K, et al. Risk of hypoglycaemia with insulin degludec versus insulin glargine U300 in insulin-treated patients with type 2 diabetes: the randomised, head-to-head CONCLUDE trial. Diabetologia. 2020;63:698-710.

12. Blonde L, Khunti K, Harris SB, Meizinger C, Skolnik NS. Interpretation and impact of real-world clinical data for the practicing clinician. Adv Ther. 2018;35: 1763-74.

13. Siegmund T, Tentolouris N, Knudsen ST, et al. A European, multicentre, retrospective, non-interventional study (EU-TREAT) of the effectiveness of insulin degludec after switching basal insulin in a population with type 1 or type 2 diabetes. Diabetes Obes Metab. 2018;20:689-97.

14. Fadini GP, Feher M, Hansen TK, et al. Switching to degludec from other basal insulins is associated with reduced hypoglycemia rates: a prospective study. J Clin Endocrinol Metab. 2019;104:5977-90.

15. Novo Nordisk Canada Inc. Product monograph: TRESIBA ${ }^{\circledR}$ FlexTouch ${ }^{\circledR} 100 \mathrm{U} / \mathrm{mL}$, Solution for injection in a pre-filled pen. 2019. https://www. novonordisk.ca/content/dam/Canada/AFFILIATE/ www-novonordisk-ca/OurProducts/PDF/tresibaproduct-monograph.pdf. Accessed July 2020.

16. McGibbon A, Adams L, Ingersoll K, Kader T, Tugwell B. Glycemic management in adults with type 1 diabetes (Diabetes Canada clinical practice guidelines expert committee). Can J Diabetes. 2018;42(Suppl 1):S80-7.

17. Lipscombe L, Booth G, Butalia S, et al. Pharmacologic Glycemic management of type 2 diabetes in adults (Diabetes Canada clinical practice guidelines expert committee). Can J Diabetes. 2018;42(Suppl 1):S88-103. 
18. Crowshoe L, Dannenbaum D, Green M, Henderson $\mathrm{R}$, Hayward $\mathrm{MN}$, Toth E. Type 2 diabetes and indigenous peoples (Diabetes Canada clinical practice guidelines expert committee). Can J Diabetes. 2018;42(Suppl 1):S296-306.

19. World Medical Association. World Medical Association Declaration of Helsinki: ethical principles for medical research involving human subjects. JAMA. 2013;310:2191-4.

20. Seaquist ER, Anderson J, Childs B, et al. Hypoglycemia and diabetes: a report of a workgroup of the American Diabetes Association and the Endocrine Society. Diabetes Care. 2013;36:1384-95.

21. Khunti K, Cigrovski Berkovic M, Ludvik B, et al. Regional variations in definitions and rates of hypoglycaemia: findings from the global HAT observational study of 27585 people with type 1 and insulin-treated type 2 diabetes mellitus. Diabet Med. 2018;35:1232-41.

22. Ratzki-Leewing A, Harris SB, Mequanint S, et al. Real-world crude incidence of hypoglycemia in adults with diabetes: results of the InHypo-DM Study, Canada. BMJ Open Diabetes Res Care. 2018;6:e000503.

23. Ostenson CG, Geelhoed-Duijvestijn P, Lahtela J, Weitgasser R, Markert Jensen M, Pedersen-Bjergaard U. Self-reported non-severe hypoglycaemic events in Europe. Diabet Med. 2014;31:92-101. 